\title{
Povos indígenas e negros nos Sertões do Leste: transição para a República e nacionalidade ${ }^{1}$
}

\author{
Indigenous and black peoples in the Sertões do Leste: \\ Transition to Republic and Nationality
}

Izabel Missagia de Mattos²

DOI: http://dx.doi.org/10.20435/tellus.v0i0.515

\begin{abstract}
Resumo: O trabalho consiste em buscar aproximações entre estudos sobre os povos chamados Botocudos nas Minas Oitocentistas e os recentes aportes sobre o estudo de quilombos na região denominada Sertões do Leste, marcada por uma colonização violenta, com a ocorrência de escravização de indígenas e de fugas de negros escravizados. Para isso são levantadas, nas fontes pesquisadas, informações relativas às complexas relações entre índios e negros que apontam para a formação de redes entre diferentes povos e suas conexões naquela região de fronteira. Esta proposta de interpretação se insere em uma tendência de estudos latinoamericanistas de articular a experiência indígena oitocentista à dos descendentes africanos, frequentemente abordados separadamente, nelas situando problemas relativos aos processos de cidadanização e transição para o trabalho livre, em um período histórico crucial para a formação da nacionalidade brasileira.
\end{abstract}

Palavras-chave: fronteira; nacionalidade; Botocudos; quilombolas; cidadania.

Abstract: The aim of the present study was to identify commonalities between the studies of the Botocudos in the Minas Oitocentistas and the recent study of the 'quilombos' on the 'Sertões do Leste' region. The latter region was marked by a violent colonization with slavery of native populations and escape of Africandescendant slaves. On these sites, the indigenous and the black populations formed connections and networks that are investigated from information collected at sources. This interpretation proposal, of articulating the experiences

1 Este artigo foi produzido em minha permanência como visiting scholar na Universidade da Carolina do Norte (UNC) em Chapel Hill, Estados Unidos. Agradeço especialmente a Cynthia Radding - líder incontestável no campo de estudos internacional e interdisciplinar das paisagens e fronteiras na história - o apoio recebido ao longo deste processo. Agradeço também à rede de pesquisa ARENET (The Americas Research Network) que propiciou a comunicação de algumas das reflexões aqui apresentadas no XXXVI Congresso Internacional da Associação de Estudos Latino-Americanos (LASA) em Barcelona, em maio de 2018.

2 Universidade Federal Rural do Rio de Janeiro (UFRRJ), Seropédica, Rio de Janeiro, Brasil. 
of the indigenous peoples with the African-descendants, is a contemporary trend of Latin-American studies. Here, i also use this new perspective to analyze the problems regarding naturalization and transition to free labor in a crucial historical period for the formation of the brazilian nationality.

Keywords: borderland; nationhood; Botocudos; quilombolas; citzenship.

\section{INTRODUÇÃO}

Parece positivo e certo o boato que corre, de se acharem no meio dos terríveis Pojichás uns negros, escravos fugidos ou mandados, que lhes dão maus conselhos, os governam e ajuntam lá no centro da perta mata de S. Mateus.

Frei Serafim de Gorizia $(1885)^{3}$

[Na missão] os índios recebem todo o auxílio possível e, insensivelmente, transformam-se em cristãos morígeros e úteis ao País.

Frei Serafim de Gorizia $(1882)^{4}$

Em um provocante ensaio que discute a pertinência da combinação entre o "Indo" e o "Afro" nos estudos latino-americanistas, a historiadora norte-americana Barbara Weinstein (2008) identifica uma tensão relativa ao campo de estudo sobre a América portuguesa e espanhola que, ademais de seus outros significados, pode ser traduzida na tendência observada entre os latino-americanistas em dividir a região entre dois lados: um primeiro, comumente associado à presença histórica e contemporânea de uma maioria indígena, e um segundo, associado à diáspora africana.

Um exame mais detido das abordagens dos "mundos indígenas" e os da chamada "diáspora africana" podem ser, de fato, reveladores da tensão apontada por B. Weinstein, pois - ainda que coexistam no tempo e no espaço investigados-, na medida em que os atores de um dos lados são enfocados, os do outro lado parecem permanecer invisíveis. Importantes aportes recentes,

3 Ofício dos diretores do aldeamento do Itambacuri dirigido ao ministro e secretário d’Estado dos Negócios da Agricultura, Comércio e Obras Públicas no Rio de Janeiro. Março de 1885. Arquivo Geral da Ordem.

4 Frei Serafim de Gorízia, ofício dirigido ao diretor geral dos índios, brigadeiro Musqueira. 3 de dezembro de 1882 (apud PALAZZOLO, 1973, p. 103). 
aqui explorados, no entanto, interrogam e iluminam facetas das inter-relações materiais e simbólicas desses atores de ambos os lados da "fronteira" étnico-racial, afro-ameríndia.

Este artigo aborda contextos ameríndios nos séculos XIX e início do XX, situados na zona etnográfica que abrange o nordeste de Minas, o norte do Espírito Santo e o Sul da Bahia, recortada por importantes vias fluviais que permitiram a navegação do interior para o oceano Atlântico, e vice-versa, na qual emergiu uma população sertaneja e nacional com origens e características étnicas bem demarcadas.

Por meio da perspectiva do middle ground (WHITE (1996), ameríndios e demais atores presentes naqueles Sertões ${ }^{5}$ podem ser considerados coparticipantes de uma mesma rede, podendo ser apreendidos, desse modo, para além de uma visão puramente dicotômica. A região, geograficamente situada nos cursos dos rios Doce, Mucuri, São Mateus, Jequitinhonha, Pardo, e seus afluentes, pode ser caracterizada como uma zona fronteiriça (borderland). Enquanto ferramenta metodológica, essa caracterização teórico-etnográfica permite abordar as relações sociais ali desenvolvidas em sua complexidade, de modo a configurarem espaços sociais e simbólicos. Determinados modelos etnocêntricos, ao valorizarem, por exemplo, a "pureza" ou "autenticidade" daqueles universos culturais em contato em detrimento da "mistura" entre os mesmos universos, podem ser superdados por meio dessa ferramenta teórica e descritiva, capaz de englobar os atores diversos em suas relações entre si e com o ambiente.

Nos dizeres da historiadora norteamericana Cynthia Radding, as zonas fronteiriças (borderlands), "tais como redes, produzem laços significativos entre povos, mercadorias, caminhos migratórios e memórias históricas que atravessam distâncias geográficas e barreiras políticas”6 (RADDING, 2017, p. 10).

5 O conceito de sertão e seus significados para a nacionalidade brasileira podem ser conferidos em Missagia de Mattos (2016).

6 "As networks, they [borderlands] trace meaningful linkages among peoples, commodities, migratory pathways, and historical memories across geographical distances and political barriers" (RADDING, 2017, p. 10). Neste sentido, como sintetizam C. Radding e D. Levin (no prelo), o conceito de fronteira requer abordagens interdisciplinares que privilegiam os processos históricos que conectam os fluxos de pessoas, bens materiais e simbólicos na constituição do mundo moderno. Para um histórico de investigações sobre os territórios de fronteira na América Latina ver Radding (2017). 
Refletindo sobre aquela região onde prevalecia a Mata Atlântica ao longo dos Oitocentos, a historiadora nipo-americana Yuko Miki (2018) a caracteriza como "fronteira atlântica", na medida em que o curso dos rios que configuram aquela paisagem fluem na direção do oceano. Com efeito, como demonstram os historiadores Ana Lúcia Côgo (2012) e Walter Pereira (2015), a chegada de africanos escravizados no porto de São Mateus, na província do Espírito Santo, em fluxo contínuo mesmo após a proibição do tráfico negreiro em 1850, indica como aquelas rotas fluviais podem ter sido utilizadas pelos fugitivos da escravização que esquadrinharam a região em busca de sobrevivência, muitas das vezes se "aquilombando" com os indígenas que recusavam o "comércio" com os pioneiros e colonos.

A definição de fronteira, tal como utilizada por Miki (frontier), possui, além disso, um sentido eminentemente político, na medida em que caracteriza aquele espaço como explicitamente contraditório ao Estado Nacional- forjado por uma elite de origem europeia-, e revelador das contradições estruturais da nacionalidade brasileira, notadamente no que diz respeito ao problema da formação de uma cidadania naquela gente facilmente identificável por seus marcadores raciais.

Entre as legislações que afetaram diretamente os povos indígenas e seus territórios ao longo daquele século no Brasil, especialmente considerando o Segundo Reinado (1845-1889), destacam-se o Regulamento das Missões, de 1845, e a Lei de Terras, de 1850. Nesse período, além do tráfico negreiro, foi abolida, finalmente, a escravidão (1888), cujos significados se inscrevem diretamente sobre os indígenas ali situados, considerados mão de obra disponível para substituir a força de trabalho africana.

No contexto de transição para a República, certos processos de racialização comuns aos segmentos indígenas e negros envolvidos na ocupação econômica daquela zona podem ser, assim, abordados em conjunto e cotejados paralelamente.

A mestiçagem ocorrida como política pública nos aldeamentos oitocentistas (MISSAGIA DE MATTOS, 2004) se relaciona, assim, tanto à perspectiva de transformação dos indígenas em "nacionais" quanto à possibilidade de uma maior exploração de sua mão de obra (principalmente se essa mestiçagem ocorre com os negros libertos), a partir da racialização dessas populações. 
Uma releitura das fontes sobre a história indígena em Minas ${ }^{7}$ - que permita nelas dimensionar a presença histórica da diáspora africana, assim como alguns de seus possíveis significados para a etnopolítica indígena-visa a identificar certos pensamentos e práticas relativas à escravidão dos indígenas ali frequentemente reportados. Tais questões, por sua vez, contribuem para a reflexão sobre o tema de uma cidadania baseada no mito de uma nacionalidade inclusiva e mestiça, expondo suas fragilidades e fissuras por meio de uma descrição histórico-etnográfica que envolve povos indígenas, quilombolas e libertos naquela paisagem sertaneja.

Quando consideramos os relatos das experiências dos atores indígenas e "nacionais pobres" na região do alto Mucuri, São Mateus e Itambacuri, ao longo da segunda metade dos Oitocentos, a "incivilidade" dos sertões, pode ser considerado mesmo o próprio projeto para a formação de subalternidades, e não uma simples "falha" no projeto nacional, inclusivo.

Sendo assim, buscamos o diálogo com investigações recentes sobre a diáspora africana na região, que aponta para certas pertinências teóricas e interdisciplinares da aproximação dos estudos sobre indígenas e quilombolas presentes naquela zona fronteiriça.

\section{A CONFIGURAÇÃO DOS INDÍGENAS NOS VALES DO MUCURI, DOCE E SÃO MATEUS, SÉCULO XIX}

A proximidade da condição de privação da liberdade do indígena à do escravo africano, por meio da dinâmica das relações de homens e mulheres escravizados ou libertos com os indígenas e outros atores foi examinada por Miki (2018) na zona de fronteira compreendida entre a Província do Espírito Santo (em sua porção norte) e a da Bahia (em seu extremo sul). Devido a suas características culturais e históricas, esta "fronteira atlântica", até o presente, pode ser considerada uma "zona etnográfica" (MISSAGIA DE MATTOS, no prelo).

\footnotetext{
Trata-se basicamente de relatos de militares, viajantes, naturalistas, administradores civis e missionários. No ano de 1992 foi realizado um exaustivo levantamento de fontes para a história dos índios em Arquivos Públicos no Brasil, organizado por John Monteiro e Manuela Carneiro da Cunha, do qual participei em Minas Gerais, mapeando tais fontes sobretudo no Arquivo Público Mineiro (MONTEIRO, 1994a).
} 
Com efeito, a presença de índios prestando serviços, e "quase reduzidos à condição de escravos", pode ser amplamente observada nos relatórios imperiais em todo o país, segundo demonstra a historiadora Patrícia Sampaio (2009). Só no Rio de Janeiro, um levantamento da Chefatura de Polícia indicava cerca de 52 índios, de ambos os sexos e de diferentes idades, vivendo em casas particulares, "[...] uns a título de agregados, outros a título de se educarem, outros, porém mui poucos, vencendo algum salário, mas todos sem ajuste por escrito, e talvez bem poucos com ele mesmo vocal" (BRITO, 1846, p. 25).

No caso em tela, interessa apontar a relação entre o fim do tráfico de africanos e o trabalho dos ameríndios, assim como os processos de racialização e seus significados na transição do "indígena" para "nacional" - tal como aparecem na documentacão oficial.

Um problema anterior é a constatação das relações espontâneas existentes entre ameríndios e africanos em períodos que antecederam à experiência dos aldeamentos, que viriam a incentivá-las oficialmente como solução para o problema da mão de obra no país, nas vésperas da abolição.

Em minhas incursões etnográficas entre os Krenak no início da década de 1980, diversas observações de campo transformaram-se em indagações que não encontravam ressonância nem na teoria antropológica, tampouco na historiografia. Parte do "espanto" causado pela constatação de sua (r)existência heroica - consideradas as permanentes hostilidades a que foram submetidos ao longo de séculos - podiam ser iluminadas por meio de estudos etnográficos. No entanto o estudo das fontes veio a contribuir enormemente para tornar visíveis as redes que teceram, no tempo e no espaço, sua organização social e cosmológica.

A existência de diversos etnônimos entre os chamados Botocudos ${ }^{8}$, com

8 Assim denominados pelos portugueses por causa do adorno labial característico, o imató, disco de madeira leve comparada ao "botoque" utilizado como rolha das garrafas de cachaça. A autodesignação deste povo para si, mas extensível para todos os ameríndios, na língua originária é Borum, que significa "gente". Ainda que esses povos tenham se tornado célebres na História e na Etnologia por meio do etnônimo Botocudo, assim eram referidos apenas na forma literária, posto que na prática dos sertões o epíteto de "bugres" foi usualmente adotado pela população regional. Em sua viagem pelo rio Doce, Paul Ehrencheich esclarece que enquanto o primeiro nome, Botocudo, "parece advir da referência aos discos de madeira leve usados como adornos pelos indígenas, parecidos com as rolhas de tonel dos portugueses (botoques), o nome bugre deve referir-se ao vocábulo bougre, que significa herético" (EHRENREICH, 2004, p. 47-8). 
efeito, remete para uma cosmopolítica ${ }^{9}$ que impele à subdivisão e a um processo de diversificação, observável, por exemplo, na diferença de aspectos fisionômicos coletivamente identificáveis - cuja análise, por exemplo, vai de encontro ao tabu das classificações raciais há muito denunciado e exorcisado pela antropologia.

Em sua visita pastoral ao aldeamento do Itambacuri em 1902, por exemplo, o então bispo de Diamantina, D. Joaquim Silvério de Souza, apontava para a diversidade existente entre os Botocudos, ressaltando que "cada secção tomava nome do seu capitão: assim é Poté, Norec, Porutum". Segundo ele, essa diversidade poderia ser apreendida em sua aparência física: seriam os Aranãs "claros em geral, cabelo preto e fino, facilmente confundíveis com brancos, tipo mais europeu que asiáticos ou chins, que é o dos outros". Os Mavões, por outro lado, seriam "em geral roxos", enquanto os Pojichás, "mais corpulentos (mas bonitos, diz frei Serafim, e maus)"10.

Dessa forma, minhas observações relativas às evidentes diferença fisionômicas existentes entre os dois principais subgrupos que compunham o povo Krenak, na década de 1980, parecia encontrar alguma ressonância, já que se tratava de um grupo recomposto a partir de subgrupos dispersos na região durante a implantação do Serviço de Proteção aos Índios e Localização de Trabalhadores Nacionais (SPILTN). Sendo assim, os Nakrehé, mais escuros, os Minhagirum, mais claros, foram levados para a área demarcada em 1920, no norte do Rio Doce, para os Krenak e Pojichás, a partir de seus lugares de origem, onde viviam ameaçados por conflitos territoriais.

Os significados de tais diferenças se inscreviam nas relações sociais e políticas, uma vez que testemunham antigas memórias de dissidências e alianças

9 O termo cosmopolítica tem sido utilizado na antropologia contemporânea para enfatizar a existência de diferentes cosmos e diferentes políticas. No caso ameríndio, a cosmopolítica está relacionada ao animismo, uma vez que todos - animais e humanos - são considerados seres com subjetividade e intencionalidade. Essas diferentes perspectivas têm por fundamento a predação, se estendendo para as relações entre todos os seres do universo, humano e não-humano, natural ou sobre-natural. A vingança caracteriza as relações com o Outro e serve para explicar processos como o adoecimento, onde a "alma" do sujeito pode ser "canibalizada" pela "alma" do animal ingerido, por exemplo, que se vinga por ter sido devorado. Nesse nível cosmopolítico se incluem também as guerras, que visam a trazem do "exterior" para o mundo interior, potências (afins) que contribuem para a construção de um sentido de identidade "consanguínea", por meio da incorporação do Outro.

10 Livro de visita pastoral de Dom Joaquim Silvério de Souza (1902-1907). Cx. 49. Arquivo Eclesiástico da Arquidiocese de Diamantina. 
naquele ambiente outrora de "selvas" do Mucuri, Doce e São Mateus, onde viveram seus antepassados.

Ao ampliar a escala espacial e histórica da investigação, passei a registrar outros fatos que pareciam significativos sobre a presença da diáspora africana relativas, por exemplo, à umbanda regional, denominada "pemba", a mim reportada por moradores não indígenas justamente por suas características "afroindígenas". Esse encontro e casamento dos deuses africanos e dos espíritos indígenas no Brasil- no dizer do antropólogo francês Roger Bastide (1973) - apesar de ter sido objeto de muita investigação em antropologia, vem sendo também estudado de maneira inovadora, à luz de conceitos caros à etnologia indígena contemporânea. Dessa forma, diferentes facetas do encontro entre os mundos indígenas e os da diáspora africana no Brasil passaram a ser revistas também no âmbito teórico da antropologia (GOLDMAN, 2014; 2015).

A constatação a respeito desses indícios de convívio secular entre ameríndios da mata atlântica e africanos permanece ainda pouco explorado na etnologia, como apontaram Carvalho, Reesink e Cavignac (2011). O caso relatado pelo inspetor do SPILTN Pedro Taulois em dezembro de 1910, ao informar sobre os grupos trabalhos de "pacificação" dos grupos indígenas do sul da Bahia, por exemplo, descreve observações nesse sentido, sobre "uma povoação chamada Uruba, entre Gongogy e Bôa Nova, que tem sido várias vezes atacada pelos índios Patachós pretos e Camacans de olhos azuis".

O mesmo inspetor iria relatar acontecimentos coetâneos relativos a uma expedição policial para capturar criminosos "que constava se tinham refugiado entre os índios". Esta expedição não apenas dizimaria 13 homens, mulheres e crianças indígenas, como ainda consta que os oficiais "profanaram o cadáver de uma mulher índia", para averiguar se esta teria "órgãos semelhantes aos nossos"11.

Outras informações referentes à memória oral ou a observações etnográficas recentes ${ }^{12}$, ainda que reportem informações congenêneres, não serão aqui

11 SERVIÇO DE PROTEÇÃO AOS ÍNDIOS. Inspetoria Regional 4. Posto Indígena Caramuru-Paraguaçu. Relatório. Bahia, 28/12/1910. Microfilme: 190. Fotograma: 82-89 (FERREIRA, 2017).

12 Trata-se de observações oriundas do projeto realizado entre 2014 e 2016 com o auxílio da Faperj, denominado "Memórias e Paisagens do Aldeamento do Itambacuri e sua região de influência, Minas Gerais". 
examinadas, já que pretendo enfocar as conexões entre os indígenas da Província de Minas com os os demais atores regionais situando-as em um contexto bem definido da historiografia social marcada pela escravidão, levando ainda em conta uma perspectiva latino-americanista de sua relação com os processos de formação da nacionalidade (cf. DE JONG; ESCOBAR OHMSTEDE, 2016).

É preciso levar em conta que a divisão político-administrativa das Províncias pouco significado tem para a circulação histórica dos povos em questão, caracterizada por grande mobilidade, já que suas territorialidades compreendiam uma situação ecológica bastante mais ampla, que englobava tanto as porções mineiras das bacias dos rios Doce, Mucuri, Jequitinhonha e São Mateus, quanto suas porções que integravam as parcelas norte da Província do Espírito Santo e sul da Bahia, também banhadas pelos rios Pardo e Alcobaça. O tráfico negreiro clandestino, aportando em São Mateus, que se tornou um polo constante de distribuição de escravos, que também dali também escapavam (CÔGO, 2012; PEREIRA, 2015).

A zona mais ampliada conhecida como Sertões do Leste pode, ainda, ser considerada uma área etnográfica que hoje abrange parte dos Estados de Minas Gerais, Espírito Santo e Bahia, caracterizada pelo fenômeno de interdigitação ou rede multiétnica - ou seja, quando a ideia de "território" não coincide com a de uma "etnia"13. Os povos habitantes naquela região de espessas florestas eram falantes dos idiomas Maxakali, Puri e Botocudo, todos filiados ao tronco linguístico-cultural Macro-Jê.

Apesar da semelhança a eles conferida por seus modos de subsistência baseados na caça e na coleta, esses povos foram observados e descritos em fontes diversificadas em seus conflituosos inter-relacionamentos por meio do trânsito de feitiçaria inimiga e guerra de vingança, que impelia a produção de diferenças. Propostas recentes em etnologia permitem interpretar tais dinâmicas sob uma mesma chave: a lógica que impele o movimento de recomposição identitária por meio de relações de aliança/vingança também configura no espaço seus

13 O conceito de área etnográfica foi proposto pelo etnólogo Júlio César Melatti, a partir dos estudos de "áreas culturais no Brasil", de Eduardo Galvão (1979). O mapa onde consta a área etnográfica "Leste" pode ser conferida em Melatti (s.d.). Já os conceitos de identidades interdigitadas e espaço geoétnico remetem aos estudos de John Murra (1975). O antropólogo chileno José Luis Martinez (1992) utilizou o conceito de "identidades interdigitadas" para demonstrar como a determinação de unidades políticas e étnicas separadas não tem pertinência em certos espaços ecológicos. 
territórios-rede - uma vez que essa cosmopolítica gera um padrão de territorialidade nômade (HAESBAERT; BRUCE, 2002).

Com o avanço da fronteira, os diversos subgrupos Botocudos se transformaram de acordo com suas estratégias, escolhas e articulações, seja com povos afins ou filiados a outras famílias linguísticas; com grupos de pioneiros mestiços que passaram crescentemente a integrar a paisagem daquela zona e disputar, de forma cada vez mais acirrada, as terras e os recursos dos indígenas; seja com escravos fugidos ou "raptados".

O relato mais antigo sobre a existência de negros entre os povos do Mucuri é de autoria do capitão-mor João da Silva Santos, que, além de informar detalhes importantes sobre a existência de uma grande aldeia na região do Alto Mucuri, descreve que lá viveu fugitivo um escravo de sua propriedade, por um ano e meio, sendo a ele "devolvido" pelos índios no ano de 1800. Esse primeiro registro já permite entrever complexidades e nuances das relações entre negros e indígenas na região (MISSAGIA DE MATTOS, 2013).

\section{ESCRAVOS INDÍGENAS E "QUILOMBOS” NOS SERTÕES DO LESTE}

[...] Naquelas matas [há] o bárbaro costume dos fazendeiros no Mucuri de incitarem os índios a pilhagem dos filhos uns dos outros para depois comprá-los a troco de insignificantes objetos como espingarda. Este costume perpetua o ódio entre as tribos, porque, não entregando os pais voluntariamente os filhos para esse infame tráfico (Kurucas), a guerra, o luto e o assassinato sempre a aquisição dos objetos para tão odiosa mercadoria.

Antonio Luiz Musqueira (1872) ${ }^{14}$

Recentemente, Andrés Reséndez (2016) publicou um estudo exaustivo sobre o apresamento de indígenas utilizados como mão de obra escrava na colonização espanhola. No Brasil, além do pioneiro e célebre Negros da Terra (MONTEIRO,

14 Relatório da catequese dos Índios em Minas Gerais, apresentado pelo Diretor Geral dos Índios, Antônio Luiz de Magalhães Musqueira ao Presidente da Província, Senador Joaquim Floriano de Godoy. Ouro Preto, Diretoria Geral dos Índios, 30 de Novembro de 1872. Arquivo da Cúria do Rio de Janeiro (apud OLIVEIRA, 2016). 
1994b) - detalhado estudo sobre o processo de apresamento e escravidão dos "índios coloniais"15 em São Paulo -, contamos com o trabalho de Leônia Resende (2003), que aborda a luta dos indígenas escravizados em Minas colonial para terem reconhecido seus direitos por liberdade ${ }^{16}$.

Desde então, um sem-número de importantes e variadas contribuições para as mais diversas regiões do Brasil podem ser contabilizadas. Referência indispensável para a interface entre história e antropologia, os estudos de Flávio dos Santos Gomes (2012; 2015), por exemplo, apontam para a realidade de imbricação dos mundos indígenas e africanos na Amazônia colonial, ao abordar os significados das fugas coletivas dos indígenas que ali formavam comunidades mestiças com africanos, em processos típicos de etnogênese.

O problema da exploração e do comércio da mão de obra indígena ao longo do período imperial, contudo, ainda é pouco conhecido, apesar de ambos terem sido amplamente praticados em Minas Gerais. A abordagem conjunta do problema do trabalho dos indígenas, dos recrutas, dos africanos livres e agregados, vem, cada vez mais, evidenciando a situação de vulnerabilidade a que estavam sujeitos esses homens livres e pobres.

Beatriz Gallotti Mamigonian (2005, p. 411) descreve como, nos Oitocentos, ao invés de um processo de "transição para o trabalho livre", diversos estatutos de homens livres (como indígenas e ex-escravos) experimentaram, na prática, "outros arranjos de trabalho forçado". No caso dos Botocudos, tais práticas seriam de extrema violência, legalizada pela Corte Portuguesa com o Decreto de Guerra Justa de 1808 (SPOSITO, 2009), há muito contabilizadas na historiografia (MARCATO, 1979; DUARTE, 1998). A infraestrutura implementada pelo Decreto de Guerra estimulou a integração territorial para que os Sertões do Rio Doce pudessem ser devassados. O trabalho compulsório mobilizado nesse empreendimento

15 “Entende-se por 'índios coloniais' aqueles 'integrados' ao mundo colonial..[porém] reconhecendo-se como herdeiros de uma origem indígena" (RESENDE, 2003, p. 3)

16 Estudos sobre apresamento dos indígenas para trabalho compulsório na América Latina colonial vêm vindo à tona nas últimas décadas. Stuart Schwartz (1978) insistiu na necessidade de se abordar em conjunto os temas da escravidão africana e indígena no Brasil, desde seu artigo pioneiro sobre o trabalho indígena na colonização do nordeste, que se seguiu a outro, com Hal Langfur (2005), na coletânea organizada por Matthew Restall (2005), Beyond Black and Red: African-Native Relations in Colonial Latin America. 
foi basicamento o dos indígenas e recrutas, e não do escravo negro (GONÇALVES; MEYER, 2011; ESPÍNDOLA, 2005).

O Diretor Geral dos Índios da Província, já na segunda metade do Século XIX, denunciava como os fazendeiros dos vales do Mucuri e Doce estimulavam guerras intertribais para que os indígenas capturassem "os filhos dos companheiros para vendê-los" "a troco de qualquer objeto de pequeno valor" e "servirem como escravos negros para o serviço da lavoura" ${ }^{17}$. Isto se deveu, inicialmente, ao fato denunciado por Auguste de Saint-Hilaire, em sua visita à região:

Abusando de uma lei que dá dez annos da vida desses selvagens aos que o retirarem da barbarie para civilizá-los [...] repetia-se então, no Brazil, o que succede na Costa D’Africa: tentados pelos preços porque os Portuguezes pagavam as creanças, os Capitões Botocudos guerreavam-se para ter creanças a vender. (SAINT- HILAIRE, 1958, p. 184). ${ }^{18}$

O tráfico das crianças dos Botocudos (kruk), reiteradamente documentado nas fontes Oitocencistas, chegou a se naturalizar no imaginário regional enquanto medida "salvacionista": a maior parte dos viajantes que por ali passou carregou consigo uma dessas crianças, algumas vezes relatando brevemente seus tristes destinos ${ }^{19}$.

Ao longo dos Oitocentos, devido à ocupação militarizada pela Guerra Ofensiva (1808-1831), a realidade de violência contra os indígenas e a devastação das matas tornaram-se irreversíveis. Como não foram criados destacamentos

17 Relatório do diretor geral dos índios, brigadeiro Antônio Luiz de Magalhães Musqueira, dirigido ao presidente da Província. 18 de fevereiro de 1875. SG 15, p. 41 . Arquivo Público Mineiro.

18 A Lei a que se refere é o Decreto de Guerra Ofensiva, de 13 de maio de 1808. Carta Régia de 13 de maio de 1808. Disponível em: http://www.planalto.gov.br/ccivil_03/revista/Rev_18/ CartaRegia_1305.htm. Acesso em: 15 set. 2015.

19 As crianças indígenas vitimadas pela guerra foram muito cobiçadas por traficantes, agricultores e até naturalistas viajantes estrangeiros. Todos estes que ali estiveram na primeira metade dos Oitocentos negociaram e levaram consigo un kruk, após negociações levada a cabo principalmente na Sétima Divisão Militar de São Miguel, no Jequitinhonha, com o próprio alferes Julião Fernandes Leão. O menino Quäck foi adquirido pelo Príncipe Maximilano de Wied Neuwied, sendo enviado para a Alemanha onde iria falecer aos 27 anos, vítima de cirrose hepática, tendo sido importante auxiliar de Wied na pesquisa lingüística e de identificação de espécies levadas da região. Saint-Hilaire também negociou um menino para levar para a Europa, após vários périplos que descreve em sua Viagem pelas províncias do Rio de Janeiro e Minas Gerais, p. 276. Já o kruk obtido pelo austríaco Johann Emanuel Pohl (1976, p. 141-2), conseguiu escapar. 
militares no vale do Mucuri e Alto São Mateus, a região permaneceu como última fronteira para os indígenas, passando também a receber um fluxo constante de lavradores pobres e ex-escravos deslocados de outras regiões da Província ou mesmo do nordeste do país, movidos pela valorização da terra. Nesse processo, inúmeros são os relatos de indígenas que se associaram aos pioneiros em empreendimentos diversos, como o de aberturas de matas e estabelecimento de povoações (RIBEIRO, 2013; MISSAGIA DE MATTOS, 2005).

A criação, em 1847, da Companhia de Navegação e Comércio do Mucuri - uma empresa de capital misto dirigida pelo político mineiro Teófilo Benedito Otoni ${ }^{20}$ - trouxe para aquelas matas, a partir de 1855 , escravos africanos e crioulos, portugueses, chineses, além de alemães, holandeses, suíços e franceses, empregados nos trabalhos com a produção agrícola e de abertura de estradas.

Diversos dos "cometimentos" e "rebeldias" de subgrupos Botocudos nas propriedades dos colonos do Mucuri relacionavam-se à presença de escravos: consta, por exemplo, que os índios os "raptavam" para devolvê-los mediante "resgate" e que, por vezes, os assassinavam. Repetidamente mencionado na correspondência da Diretoria dos Índios, um dos massacres registrados contra os Pojichá foi realizado na fazenda do capitão Leonardo Otoni, em outubro de 1885, tendo sido mortos 37 índios, após o resgate de um escravo por eles "raptado" (SASSOFERRATO, 1915, p. 53). Sobre esses episódios, conta a memorialista Célia Weyrauch (1997, p. 90) que um negro fugido da Fazenda Liberdade, por ter matado uma onça, conquistou prestígio entre os Pojichás, que passaram chamar-Ihe de "Capitão Grande", a quem seguiram na invasão da Fazenda com o intuito de matar o Capitão Leonardo e raptar-Ihe as filhas.

Em correspondência ao presidente da Província, o diretor dos índios do Mucuri, Augusto Otoni, relatou, no ano de 1861, os esforços da Companhia do Mucuri para conter o tráfico de curucas (kruk, na língua indígena):

Outra providência escrupulosa e geralmente cumprida é a proibição de tomar aos índios os filhos para os conservar em mal disfarçada escravidão,

20 Teófilo Benedito Otoni nasceu em Serro, Minas Gerais (1807) e faleceu no Rio de Janeiro (1869). Filho de comerciante, Otoni freqüentou a Academia de Marinha do Rio de Janeiro, tendo sido eleito deputado pela Província de Minas em 1835 e deputado geral na quarta, quinta e sétima legislatura. Em 1842, foi preso e acusado como um dos chefes da Revolta Liberal. 
ou para os remeter para longes terras, ora como mercadoria de comércio, ora como presente de festas que se costuma fazer aos potentados. Cuido poder asseverar a V. Ex cia que, do meu distrito e durante minha direção ainda não saiu um indiosinho (kuruka). (apud EMMERICH; MONTSERRAT, 1975, p. 49-50).

As crianças eram tomadas dos indígenas pela elite local como "presente de festas" ou força de trabalho de potencial utilidade para a agricultura local; por essa razões, sua relação com os escravos negros precisa ser equacionada. Ainda que fossem pequenos os plantéis existentes no Mucuri, a ocorrência frequente de rebeldias e fugas nas fazendas da região foi registrada. A rota de fuga dos escravos negros era a mata, onde a sobrevivência se fazia possível por meio da aliança com os indígenas. Márcio Achtschin, por meio de pesquisa documental, analisou evidências de escravos fugidos convivendo com os indígenas, na época da Companhia do Mucuri (ACHTSCHIN, 2006).

Por outro lado, estudos sobre quilombos na região dos Sertões do Lestecomo os realizados por Miki (2018; 2014; 2012)- permitem demonstrar como eles também mantiveram redes de comunicação complexas que incluíram indígenas, auxiliando para refutar a ideia de constituirem núcleos "isolados". As comunidades quilombolas, segundo a autora, faziam parte de redes, articulando-se inclusive a outro atores no interior do sistema escravista.

Segundo Vânia Moreira (2014), as fugas dos escravos registradas em toda a Província do Espírito Santo eram motivo de muito inquietamento para as autoridades. Somada a essa tendência, também havia índios moradores das vilas pombalinas no Espírito Santo (Benevente e Reis Magos), obrigados ao trabalho compulsório como uma espécie de tributo, que por vezes, como um último recurso, se evadiam, já que eram por demais pesados os serviços a que eram obrigados, como transportar terra e abrir estradas.

O presidente da Província do Espírito Santo, tendo percorrido com o diretor dos índios, o Barão de Itapemirim - grande proprietário de terras e escravagista -, as Vilas de São de Mateus e Linhares, localizadas na porção norte do baixo Rio Doce, registrou, no ano de 1848, como considerava "avultado" o número de Botocudos que povoavam aquelas matas. Ainda assim, notava sua diminuição 
relativa aos tempos coloniais por terem "se retirado para as bandas do Mucuri", seja porque não encontravam no aldeamento da Beririca, "os suprimentos que esperavam obter", seja por ainda se encontrarem aterrorizados pelas práticas dos colonizadores do início do século XIX. Os Botocudos que permaneceram naquela região - observava o presidente da Província:

Encontravam-se espalhados por casas e fazendas particulares, onde trabaIham... Há mesmo já algum comércio entre eles e os habitantes da vila, a qual levam ervas ${ }^{21}$ e outros objetos, que tiram das matas, em trocas dos quais recebem mantimentos, ferramentas e outras coisas. Costumam às vezes alugar-se como trabalhadores de machado e foice para as derrubadas. ${ }^{22}$

Este relato, por si só, torna evidente a importância da mão-de-obra dos indígenas para a exploração econômica daquela zona fronteiriça, uma vez que se empregavam com frequência em atividades extrativistas que geravam grande lucro para seus contratadores. "Bem cotada no comércio" - nos dizeres de Nelson de Senna (1910, p. 13) - até o século XX, a poaia era uma das chamadas "ervas do sertão" em abundância naquela região e espessa floresta atlântica. Segundo denunciou o bispo de Mariana dom Domingos da Encarnação Pontevel, o produto - que a muitos fazendeiros enriqueceu- era obtido à "custa de braços daqueles mesmos que engodam, em alguns pedaços de lençóis, chitas a troco de imensos quintais de poaia extraída pelos mesmos [índios] que depois de tantos suores ficam iludidos com algumas porções de aguardentes" ${ }^{\prime 23}$.

A situação descrita acima para os Botocudos do norte do Espírito Santo, em movimento de fuga para o Mucuri- onde ainda não havia projetos oficiais de

21 Trata-se das raízes da Cephäelis ipecacuanha. "Em épocas certas" - esclarecia o botânico G. W. Freireyss - "[os portugueses que fazem bons negócios com o comércio dessa droga] reúnem para este fim a maior porção possível de índios e atravessam com eles as matas. Nestas excursões levam sempre mantimentos e especialmente aguardente que vantajosamente vendem em troca das provisões de ipecacuanha que os índios fizeram, por um pequeno cálice de aguardente - uma mercadoria cuja venda aos índios é proibida - recebem por vezes $1 / 4$ de libra da valiosa raiz" (FREIREYSS, 1901, p. 245).

22 Relatório do Presidente da Província do Espírito Santo, Luís P. do Coutto Ferraz (01/03/1848, p. 23-25). Disponível em: https://ape.es.gov.br/Media/ape/PDF/Relatorios/LUIZ\%20PEDREIRA\%20 DO\%20COUTTO\%20FERRAZ\%20-\%20Presidente\%20da\%20Prov\%C3\%ADncia.pdf/. Acesso em: 28 abr. 2018.

23 Arquivo da Câmara Municipal de Mariana. Epistolário dos Governos Episcopais, D. Domingos Pontevel (1779-1793) (apud RESENDE, 2003, capítulo 2). 
colonização- precisa ser articulada à "forte resistência dos escravos às condições impostas pelo cativeiro" ali registrada na década de 1840 (CÔGO, 2012, p. 111).

Aquela, de fato, em todo o Século XIX, permaneceu uma região de fronteira marcada pela violência e impunidade, que perdurou todo o século seguinte. "Escravos do mato" e "índios hostis" impunham resistência à exploração da mão de obra e muita força repressiva foi contra eles utilizada. Para Moreira (2014), o problema da segurança pessoal e pública constituiu uma das principais preocupações dos moradores e autoridades do Espírito Santo, que enfrentaram o problema com estratégias variadas, por vezes, inclusive, armando os próprios escravos contra os indígenas. Sendo assim, ora os indígenas eram recrutados nas vilas para combaterem os negros fugidos, ora os próprios escravos (e quilombolas) tornaram-se "caçadores" de índios.

Todas essas contradições se inscreveram na experiência da missão do Itambacuri (1873-1911) (MISSAGIA DE MATTOS, 2004) e podem ser depuradas dos acontecimentos que ali tiveram lugar, de acordo com as considerações do missionário diretor do Itambacuri, Frei Serafim de Gorízia (1882):

Pouco melhor educação recebem aqueles [índios] que se acham em casas dos particulares, salvo alguma exceção; quando que este soberbo lugar em tão excelentes terras, que se estendem para mui longe em todas as direções nesta mata virgem, mormente na do rio Doce ao sul, e a leste na de S. Mateus (Serras Aimorés), cabe e abrange quantos indígenas há para aldear, ajuntando-se todos aqui e procurando-lhes de terem sido suficientemente instruídos, alianças religiosas e morais com famílias nacionais de bons lavradores segundo o que já se pratica...

Os missionários diretores do Aldeamento Central Nossa Senhora dos Anjos do Itambacuri chegaram a reportar às autoridades a presença de escravos fugidos entre os Pojichá:

Obsequiosamente acrescentamos à humilde e verídica relação de 15 do corrente mais esta notícia, que parece positivo e certo o boato que corre, de se acharem no meio dos terríveis Pojichás uns negros, escravos fugidos ou mandados, que lhes dão maus conselhos, os governam e ajuntam lá no centro da perta mata de S. Mateus... ${ }^{24}$

24 Ofício dos diretores do aldeamento do Itambacuri dirigido ao ministro e secretário d’Estado dos Negócios da Agricultura, Comércio e Obras Públicas no Rio de Janeiro. Março de 1885. 
A convivência entre indígenas e negros, de fato, pode ser percebida pelas fotos das "bugrinhas" acolhidas no orfanato em Itambacuri em 1910, filhas dos indígenas "descidos" das matas do São Mateus. Estes seriam as filhas dos Pojichá, último grupo Botocudo aldeado em Itambacuri e massacrado no início do século $X X$.

Foto 1 - Asilo de Indígenas e Órfãs. Colégio Santa Clara - década de 1910

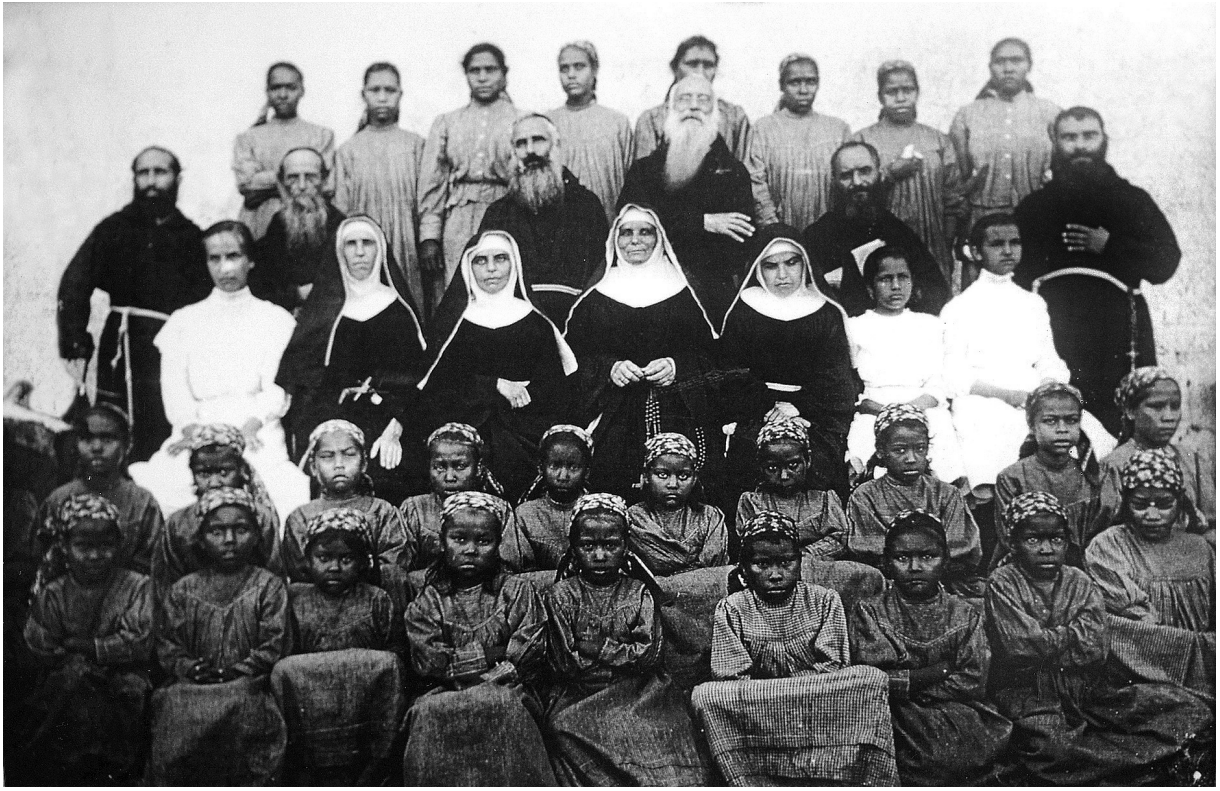

Na segunda fileira, os fundadores do Itambacuri, Frei Serafim de Gorízia (ao centro, de longas barbas brancas) e Frei Ângelo de Sassoferrato (segundo, da esquerda para a direita). Fonte: Arquivo do Colégio Santa Clara, Itambacuri, MG.

\section{RAÇA “CRUZADA" E POVO “MORIGERADO": DA REVOLTA INDÍGENA À REPRESSÃO DA DIVERSIDADE CULTURAL/LINGUÍSTICA}

No seu tempo, muitos menores alunos obtiveram conhecimentos úteis a respeito a instrução primária; entre os quais alguns há que ocupam cargos, porém se acanham em dizer que foram instruídos e educados por um professor índio ou indígena; mas não deve-se admirar sobre essa frase; porque muitos que

Arquivo Geral da Ordem. 
aqui existem ainda no Itambacury, quase todos são mistos ... Perguntando-se a respeito índios e parentescos donde provêm, respondem diversamente excluindo-se fora de suas aldeias para se embrenharem nas senzalas dos índios que vieram da costa de do centro da África, porém a fisionomia e os gestos garantem sempre que descendem da aldeia dos índios, progenitores das nações que ocupavam o Brasil, quando desembarcou na América o Almirante Pedro Álvares Cabral em 1500...

Domingos Ramos Pacó (1918)

Durante a segunda metade do Século XIX, as nações latino-americanas concretizavam suas políticas de conquista sobre territórios até então ocupados pelos indígenas, em um acentuado processo de "colonialismo interno" liderado pelas elites políticas e econômicas. A discussão sobre o tema da cidadania, segundo as tendências atuais, permitem abordar o problema da subordinação tanto dos sujeitos indígenas quanto os dos oriundos da escravidão (DE JONG; ESCOBAR OHMSTEDE 2016). As Constituições e o Direito das novas nações, mais colonialistas que a própria empresa europeia, garantiram grande parte desses intentos de subjugar os índios e promover a privatização de suas terras (CLAVERO, 1994, p. 23).

No Brasil, os historiadores do período têm também reconhecido que a opção dos construtores do Estado pela ordem conservadora, escravocrata e controladora da população livre pobre resultou em profundas restrições para uma possibilidade de cidadania liberal capaz de incorporar índios e libertos ao corpo da nação (MATTOS, 2004).

O evento dramático, que condensa vários elementos importantes para essa discussão e para o qual converge a discussão proposta, foi a revolta indígena no Aldeamento Central Nossa Senhora dos Anjos do Itambacuri, que eclodiu no dia 24 de maio de 1893, após vinte anos de sua fundação. Diversas vezes anunciada e sempre temida pelos seus diretores, missionários capuchinhos italianos, a revolta deflagrada por meio de uma conexão de relações entre indígenas e outros atores ali presentes, como ex-escravos, flagelados e retirantes - denominados "nacionais pobres" pelos missionários. A missão foi franqueada a toda essa gente devido à finalidade explícita da formação local de uma "raça cruzada", que resultaria, segundo os missionários, em um "povo morigerado" e obediente às normas. Um 
processo utópico, por vezes justificando-se na profecia bíblica da "terra prometida", de formação de uma casta pobres, de subalternos úteis ao país.

A situação crítica vivida pelo aldeamento no ano de 1891 quando grassava a fome e epidemias entre indígenas e "nacionais" parece, de fato, desesperadora, além de epidemias de sarampo que ceifaram a vida de mais de 400 indígenas. Os "nacionais pobres" - nem sempre discriminados segundo a cor ou critérios "raciais" na documentação pesquisada - chegavam incessamente ao local, segundo relato do diretor missionário ao seu superior na Ordem,

[...] afluíam dos sertões a matar aqui a fome, causada pela terrível e desastrosa seca que houve, chegando uns a tal desespero de se nutrirem de frutas, raízes, cascas selvagens, nocivas e venenosas, e até de carne humana, definhando nos caminhos quando iam procurar sustento, ou morrendo em suas casas sem que pudessem prestar socorro uns aos outros dos que compunham a família, ficando pois os cadáveres insepultos, para os devorarem feras e urubus. Nosso hospício viu-se todos os dias sitiado pelos infelizes, verdadeiros espectros ambulantes, que buscavam remédio e socorro à alma e ao corpo, e levaram-no ao desalento e total apuro de recursos até a presente data ${ }^{25}$.

Esse projeto dos missionários, já na nascente República, no entanto, sofria resistências tanto de oponentes poderosos, interessados nas riquezas do local, como dos "malévolos" índios "rebeldes" e portadores de "maus costumes", impermeáveis aos "bons conselhos" e à "conversão".

A Diretoria dos Índios da Província de Minas, defensora da implantação da catequese missionária no local, entendia que os indígenas eram os "verdadeiros colonos que os poderes gerais [deveriam] de esforçar-se por adquirir" por serem "aclimatados" e se contentarem "com uma alimentação frugal" e "vestuário simples". Assim, o desafio imposto aos missionários era o de administrar doses necessárias de "disciplina civilizatória" capazes de converter os "brutos, vadios e perigosos" indígenas em futuros "moralizados e domésticos trabalhadores" ${ }^{26}$. Nesse sentido, a estratégia da mestiçagem "racial", para "amansar" o temperamento

25 Frei Serafim de Gorízia. Relatório do aldeamento indígena, dirigido ao ministro geral da Ordem. Agosto de 1891. Arquivo Geral da Ordem.

26 Relatório do diretor geral dos índios José Januário de Cerqueira. 17 de fevereiro de 1886. Anexo ao relatório do presidente da Província à Assembléia Provincial. Arquivo Nacional. 
indígena e promover a construção de uma nação "mestiça" e apta para a indústria movida por "braços aclimatados" não apenas foi adotada como amplamente propagada pelo país.

Uma das etapas mais significativos da Revolta de 1893 foi seu o processo de preparação, por meio de um paciente movimento que passou a reunir e incorporar os moradores indígenas dispostos em distâncias de mais de 30 quilômetros às margens do rio Itambacuri, em número aproximado de 2000, que vieram a se alocar, "entrincheirados", próximo à sede da missão (MISSAGIA DE MATTOS, 2004).

A circunstância de todos os episódios violentos que tiveram lugar naquela zona pioneira, onde o exercício do poder através da violência física inscreveu-se durante todo o século de ocupação, não pode ser fortuita. A imposição de fronteiras estaduais e limites e de propriedades privadas, bem como a existência de terrenos contestados na divisa entre Minas Gerais e Espírito Santo permaneceram fontes de conflitos até o século seguinte (PEREIRA, 1980).

Durante a revolta, as crianças indígenas que estavam no orfanato foram distribuídas pelas autoridades entre as famílias das proximidades já que, desde o início, o principal mote para a "civilização" era a "diluição" da "raça indígena" até que a resistência que impunha desaparecesse por completo.

As críticas e denúncias dos regionais à catequese indígena eram dirigidas, por exemplo, ao cerne de seu propósito de instrução, pois a "língua paupérrima" continuava ali a ser usada. Este argumento "linguístico" também foi utilizado em Minas contra os africanos, considerados "boçais" por não poderem argumentar a favor de si próprios em seus processos por liberdade (GONÇALVES; MEYER, 2011, p. 7). Essas críticas se transformariam em uma justificativa em favor da marginalização de seus direitos e a favor da continuidade de antigas práticas, como as de "educar" as crianças indígenas em casa de "boas" famílias.

O próprio frei Serafim relatou ao bispo D. Silvério por ocasião de sua visita de 1902 que "tinha alguma coisa apontada para um Dicionário e Gramática sobre a língua indígena". Com a revolta e a transição para a República, que o feriram de morte, admitiu que "após o flechamento rasgou tudo".

Demonstrando temor às ameaças que representavam a separação entre o Estado e a Igreja, os missionários passavam a relatar aos superiores os 
"progressos" prometidos por sua obra de civilização indígena, que acreditavam "concorrer para a felicidade e o desenvolvimento material e espiritual da grande Nação Brasileira ${ }^{27}$.

Por fim, para justificar a permanência dos missionários, outras provas de suas boas obras seriam defendidas pelo engenheiro Felício dos Santos, que, em artigo publicado no jornal "A União" em abril de 1913, assim avaliava a missão realizada:

Com ótimo critério insiste Frei Serafim no sistema de mestiçagem do elemento indígena com os nacionais. Único meio de conservar essa raça como fator de população e riqueza nacional. Mostra ele como, apesar de todos os cuidados, tem se reduzido a população puramente indígena, ao passo que a raça cruzada cresce admiravelmente. (apud PALAZZOLO, 1973, p. 274).

A violenta repressão policial à revolta ocorreu, como em muitas outras partes da República, dizimando os indígenas e transformando os que lá permaneceram em pedintes isolados, vivendo da "caridade" do Estado brasileiro e da Igreja. A "raça cruzada" que se formou e se espalhou por municípios criados no vasto território do antigo aldeamento, alguns dos quais com índices críticos de desenvolvimento humano e conflitos ambientais com o esgotamento dos recursos naturais promovidos por décadas de desmatamento. A lei ali continua sendo a do medo, silêncio e "obediência" dos pobres aos potentados locais.

\section{5 À GUISA DE CONCLUSÃO: A TRANSFORMAÇÃO DO INDÍGENA EM "NACIONAL" NA TRANSIÇÃO PARA A REPÚBLICA}

A expropriação da terra, da força de trabalho, da cultura ou da própria vida do índio tem sido facilitada pela ideologia racial dos beneficiários diretos e indiretos do desenvolvimento extensivo do capitalismo.... que acreditam que o índio é um ente da natureza ou estrangeiro fora do lugar. (IANNI, 1979, p. 200)

Este estudo pretendeu iluminar certos aspectos da etnologia no Brasil ao enegrecer algumas análises de processos envolvendo os povos Botocudos na transição para a República.

27 Frei Serafim de Gorizia, carta ao ministro geral da Ordem dos capuchinhos, frei Bernardo de Andematt. 20 de outubro de 1890. Arquivo Geral da Ordem. 
Não se trata de tarefa simples, por diversas circunstâncias metodológicas e teóricas. O tema da racialização das pessoas em certos contextos de interação tem sido abordado com sucesso a partir de observações etnográficas de pesquisadores negros. Jean Muteba Rahier (2017) aponta, por exemplo, como os estudos sobre os indígenas e os negros na história raramente encontram abordagens englobadoras, tornando invisível a presença dos negros nas investigações sobre as populações indígenas em países andinos.

Os contextos indígenas do século XIX e início do século XX aqui enfocados situaram-se em uma zona etnográfica onde emergiriam formações populacionais "sertanejas", visando a analisar certos processos de racialização comuns aos segmentos indígenas e negros envolvidos em sua ocupação econômica.

A ausência pode ser uma força de racialização tão poderosa quanto a presença. Como tal, o racismo pode funcionar, por vezes, através de um processo de substituição, um encadeamento de frases e termos que encerram significados racistas sem, no entanto, referências específicas a crenças racistas. (KEITH, 2002, p. 330).

O alcoolismo, a promiscuidade sexual, a vagabundagem e a criminalidade definiriam os principais traços da labuta pela sobrevivência dos indivíduos negros no período pós-abolição, descartados do mercado ante a concorrência da mão de obra imigrante (FERNANDES, 2008). A condição de marginalidade social dos negros em São Paulo, estudada por Florestan Fernandes, pode ser também verificada amplamente nas populações indígenas na história, na região pesquisada, e também em períodos recentes, como apontou Octávio lanni relativamente à condição de populações indígenas na Amazônia atropeladas pelo desenvolvimentismo que caracterizou as décadas de 1970 e 80, com a abertura de estradas e diversos empreendimentos na região.

Os estereótipos atribuídos aos negros continuaram a desempenhar importante papel na definição de suas possibilidades de acesso a diferentes tipos de ocupação. O avanço do capitalismo não desnivelou as desigualdades de oportunidades para negros e não negros. As atitudes discriminatórias são escamoteadas e difíceis de perceber, por exemplo, no recrutamento de pessoal. A historiadora e antropóloga negra Caetana Damasceno demonstrou como o requisito da "boa aparência"- expressão ainda presente em certos anúncios de emprego - serve 
para excluir homens e mulheres negros por não corresponderem aos padrões estéticos ideiais, socialmente definidos.

Apesar das sujeições e violências, indígenas e afro-brasileiros elaboraram estratégias e acionaram recursos variados, buscando defender seus direitos de homens e mulheres livres. (MATTOS; RIOS, 2004).

Decisivo para o "estabelecimento de critérios diferenciados de cidadania e para a construção de lugares sociais qualitativamente distintos" (ALBUQUERQUE, 2009), o processo de racialização pode ser observado em todo o período estudado nas interações entre os atores daquela zona de fronteira, influenciando negociações e conflitos que os envolveram.

\section{FONTES DOCUMENTAIS}

\section{Documentos manuscritos}

\section{Arquivo Público Mineiro, Belo Horizonte.}

Códices da Seção Provincial (1821-1890)

Documentação encadernada:

Códices da Secretaria de Governo (1863-1894):

SG 04: expediente da Diretoria Geral dos Índios da Província de Minas Gerais (18631869);

SG 15: expediente da Diretoria Geral dos Índios (1874-1878);

\section{Arquivo dos Capuchinhos do Rio de Janeiro.}

Gav. 20. Pasta II. Doc.25.

Frei Serafim de Gorízia. Relatório do aldeamento central indígena N. S. dos Anjos. 2 de janeiro de 1882.

\section{Arquivo Eclesiástico da Arquidiocese de Diamantina.}

Caixa 49

Livro de visita pastoral de Dom Joaquim Silvério de Souza (1902-1907).

\section{Arquivo Geral da Ordem Capuchinha, Roma}

Istituto Storico dei Frati Cappuccini, Pasta H 85:

Ofício dos diretores do aldeamento do Itambacuri dirigido ao ministro e secretário d’Estado dos Negócios da Agricultura, Comércio e Obras Públicas no Rio de Janeiro. Março de 1885.

Frei Serafim de Gorizia. Carta ao ministro geral da Ordem dos capuchinhos, frei Bernardo de Andematt. 20 de Outubro de 1890. 
Frei Serafim de Gorizia. Relatório do aldeamento indígena, dirigido ao ministro geral da Ordem. Agosto de 1891.

\section{Arquivo Nacional, Rio de Janeiro}

Relatórios dos presidentes da Província de Minas Gerais. Fundo "Exposições, Falas, Mensagens e Relatórios Provinciais/Estaduais".

\section{REFERÊNCIAS}

ACHTSCHIN, Márcio Santos. Mucuri: sociabilidades e cotidiano escravo no século XIX. 2006. Dissertação (Mestrado em História) - Universidade Severino Sombra (USS), Vassouras, MG, 2006.

ALBUQUERQUE, Wlamyra R. O jogo da dissimulação: abolição e cidadania negra no Brasil. São Paulo: Companhia das Letras, 2009

BASTIDE, Roger. Estudos afro-brasileiros. São Paulo: Perspectiva, 1973.

BRITO, Joaquim Marcelino de. Relatório da Repartição dos Negócios do Império apresentado à Assembléia Geral Legislativa na 3a sessão da Ga legislatura pelo Ministro e Secretário de Estado e Negócios do Império. Rio de Janeiro: Typographia Nacional, 1846. Disponível em: https://archive.org/details/rminimperio1846. Acesso em: 28 abr. 2018.

CARVALHO, Maria Rosário; REESINK, Edwin; CAVIGNAC, Julie (Org.). Negros no mundo dos índios: imagens, reflexos, alteridades. Natal, RN: EDUFRN, 2011.

CLAVERO, Bartolomé. Derecho indígena y cultura constitucional en América. México, D.F.: Siglo XXI Editores, 1994.

CÔGO, Anna Lúcia. História agrária do Espírito Santo no século XIX. A região de São Mateus. 2012. p. 111. Tese (Doutorado em História) - Univesidade de São Paulo (USP), São Paulo, 2012.

DE JONG, Ingrid; ESCOBAR OHMSTEDE, Antonio (Org.). Las poblaciones indígenas en la conformación de las naciones y los Estados en la América Latina decimonónica. Ciudad de México: El Colegio de México/El Colegio de Michoacán/CIESAS, 2016.

DUARTE, Regina Horta. Histórias de uma guerra: os índios Botocudos e a sociedade Oitocentista. Revista de História, São Paulo, n. 139, p. 35-53, 1998.

EHRENREICH, Paul. Índios Botocudos do Espírito Santo no século XIX. Vitória, ES: Ed. IHGES, 2004. (Coleção Canaã, v. 21). 
EMMERICH, Charlotte; MONTSERRAT, Ruth. Sobre os Aymorés, Kréns e Botocudos. Notas Linguísticas. Boletim do Museu do Índio, Rio de Janeiro, n. 3, p. 5-42, 1975. Antropologia.

ESPÍNDOLA, Haruf Salem. Sertão do Rio Doce. Bauru, SP: Edusc/Univale/Instituto Terra, 2005.

FERNANDES, Florestan. A integração do negro na sociedade de classes (O legado da "raça branca"). 5. ed. São Paulo: Globo, 2008.

FERREIRA, Talita Almeida. Contato, territorialização e conflito no Posto Indígena CaramuruParaguassú: Baenã, Gueren, Kamakan, Maxakali, Pataxó e índios de antigos aldeamentos no sul da Bahia, 1910-1936. 2017. 229 f. Dissertação (Mestrado em História)- Universidade Federal Rural do Rio de Janeiro (UFRRJ), Seropédica, RJ, 2017.

FREIREYSS, George Wilhem. Viagem a varias tribus de selvagens na capitania de Minas Gerais; permanência entre ellas, descripção de seus usos e costumes. Revista do Instituto Histórico e Geográfico de São Paulo, São Paulo, v. VI, p. 236-52, 1901.

GALVÃO, Eduardo. Áreas culturais indígenas do Brasil: 1900-1959. In: . Encontro de sociedades: índios e brancos no Brasil. Rio de Janeiro: Paz e Terra, 1979. p. 193-228.

GOLDMAN, Marcio. "Quinhentos anos de contato": por uma teoria etnográfica da (contra) mestiçagem. Mana, Rio de Janeiro, v. 21, n. 3, p. 641-59, 2015.

GOLDMAN, Marcio. A relação afroindígena. Cadernos de Campo, São Paulo, n. 23, p. 213-22, 2014.

GOMES, Flávio. Mocambos e quilombos: uma história do campesinato negro no Brasil. São Paulo: Claro Enigma, 2015.

GOMES, Flávio. Indígenas, africanos y comunidades de fugitivos en la Amazonia colonial. Historia y Espacio, [S.I.], v. 6, n. 34, p. 1-21, 2012.

GONÇALVES, Andréa Lisly; MEYER, Marileide Lázara Cassoli. Nas fímbrias da liberdade: agregados, índios, africanos livres e forros na Província de Minas Gerais (século XIX). Varia Historia, Belo Horizonte, v. 27, n. 46, p. 645-63, jul./dez. 2011.

GORÍZIA, Frei Serafim de. Relatório do aldeamento central indígena N. S. dos Anjos. 2 de Arquivo dos Capuchinhos do Rio de Janeiro, Gav. 20, Pasta II, Doc. 25, janeiro de 1882. 
HAESBAERT, Rogério; BRUCE, Glauco. A desterritorialização na obra de Deleuze e Guattari. Unbral Fronteiras, [S.I.], dez. 2002. Disponível em: http://unbral.nuvem.ufrgs.br/base/ items/show/1545. Acesso em: 21 fev. 2019.

IANNI, Octavio. Ditadura e agricultura: o desenvolvimento do Capitalismo na Amazônia, 1964-1978. Rio de Janeiro: Civilização Brasileira, 1979.

KEITH, Michael. The mirage at the heart of the myth? Thinking about the White City. In: GOLDBERG, David; SOLOMOS, John (Ed.). A companion to racial and ethnic studies. Massachusetts e Oxford: Blackwell Publishers, 2002. p. 323-39.

MAMIGONIAN, Beatriz Gallotti. Revisitando a "transição para o trabalho livre": a experiência dos africanos livres. In: FLORENTINO, Manolo (Org.). Tráfico, cativeiro e liberdade: Rio de Janeiro, séculos XVII-XIX. Rio de Janeiro: Civilização Brasileira, 2005. p. 389-417.

MARCATO, Sônia de Almeida. A repressão contra os Botocudos em Minas Gerais. Boletim do Museu do Índio, Rio de Janeiro, n. 1, maio 1979. Ministério do Interior/FUNAI.

MARTINEZ, José Luis. Acerca de las etnicidades en la puna árida en el siglo XVI. In: ARZE, Silvia et. al (Org.). Etnicidad, economía y simbolismo en los Andes. La Paz, Bolívia: Hisbol/ IFEA/SBH/ASUR, 1992. p. 35-65.

MATTOS, Hebe Maria; RIOS, Ana Maria. O pós-abolição como problema histórico: balanços e perspectivas. Topoi. Revista de História, Rio de Janeiro, v. 5, n. 8, p. 170-98, jan./jun. 2004.

MATTOS, Hebe. Escravidão e cidadania no Brasil monárquico. Rio de Janeiro: Jorge Zahar, 2004.

MELATTI, Julio Cezar. Áreas Etnográficas da América Indígena. Brasília, [s.d.]. Disponível em: http://www.juliomelatti.pro.br/areas/00areas.pdf. Acesso em: 9 abr. 2015.

MIKI, Yuko. Frontiers of citizenship: a black and indigenous history of postcolonial Brazil. New York: Cambridge University Press, 2018.

MIKI, Yuko. Slave and citizen in black and red: reconsidering the intersection of african and indigenous slavery in postcolonial Brazil. Slavery \& Abolition, [S.I.], v. 35, n. 1, p. 1-22, 2014.

MIKI, Yuko. Fleeing into black slavery: the insurgent geographies of brazilian quilombolas (Maroons), 1880-1881. The Americas, [S.I.], v. 68, n. 4, 2012. 
MISSAGIA DE MATTOS, Izabel. Indígenas do deserto e do sertão nos contextos de formação de nacionalidades, século XIX. Habitus, Goiânia, GO, v. 14, n. 2, p. 213-26, jul./dez. 2016.

MISSAGIA DE MATTOS, Izabel. Povos em movimento nos sertões do Leste. In: LAGE DE RESENDE, Maria Efigênia; VILLALTA, Luiz Carlos. História de Minas Gerais: a Província de Minas. Belo Horizonte: Autêntica/Companhia do Tempo, 2013. p. 71-98.

MISSAGIA DE MATTOS, Izabel. A presença dos Aranã nos registros históricos. Habitus, Goiânia, GO, v. 3, n. 1, p. 41-79, jan./jun. 2005.

MISSAGIA DE MATTOS, Izabel. Civilização e revolta: os Botocudos e a catequese na Província de Minas. Bauru, SP: Edusc, 2004.

MISSAGIA DE MATTOS, Izabel. Colonization, mediation, and mestizaje in the borderlands of Nineteenth-Century Minas Gerais, Brazil. In: RADDING, C.; LEVIN, D. Borderlands of the Iberian World: environments, histories, cultures. New York: Oxford University Press. [S.d.]. [No prelo].

MONTEIRO, John. Guia de fontes sobre história indígena em arquivos públicos brasileiros, acervos das capitais. São Paulo: NHII-USP/Fapesp, 1994a.

MONTEIRO, John. Negros da Terra: índios e bandeirantes nas origens de São Paulo. São Paulo: Companhia das Letras, 1994b.

MOREIRA, Vânia Maria Losada. Entre índios e escravos armados: Alianças interétnicas e formação de quilombos na província do Espírito Santo, 1808-1850. Luso-Brazilian Review, Madison, Wisconsin, EUA, v. 51, n. 1, p. 36-67, 2014.

MURRA, John. El control vertical de un máximo de pisos ecológicos en la economía de las sociedades andinas. In: MURRA, John. Formaciones económicas y políticas del mundo andino. Lima: IEP, 1975.

OLIVEIRA Tatiana Gonçalves de. O aldeamento dos índios de Itambacuri e a política indigenista na Província de Minas Gerais (1873-1889). 2016. 121 f. Dissertação (Mestrado em História) - Universidade Federal de Juiz de Fora (UFJF), Juiz de Fora, MG, 2016.

PALAZZOLO, Jacinto de. Nas selvas dos vales do Mucuri e do Rio Doce. Como surgiu a cidade de Itambacuri, fundada por Frei Serafim de Gorizia, Missionário Capuchinho (18731952). São Paulo: Companhia Editora Nacional, 1973.

PEREIRA, Walter L. C. Mattos. A trama do tráfico ilegal de africanos na Província do Espírito Santo (1850/1860). In: CONGRESSO DE HISTÓRIA ECONÔMICA, 11., 14-15 
set. 2015, Vitória, ES. Comunicação [...]. Disponível em: http://www.abphe.org.br/ arquivos/2015_walter_luiz_carneiro_mattos_pereira_a-trama-do-trafico-ilegal-deafricanos-na-provincia-do-espirito-santo-1850_1860.pdf

PEREIRA, Carlos Olavo da Cunha. Nas terras do rio sem dono. Belo Horizonte: Vega, 1980.

POHL, Johann Emanuel. Viagem no interior do Brasil. São Paulo: EDUSP, 1976.

RADDING, Cynthia; LEVIN, Danna (Org.). Borderlands of the Iberian World: environments, histories, cultures. New York: Oxford University Press. [No prelo].

RADDING, Cynthia. Naturalizing borderlands in time and space: imperial frontiers and historical indigeneities in the America. Habitus, Goiânia, GO, v. 14, n. 2, p. 5-19, jan./jun. 2017. RAHIER, Jean Muteba. Mas allá del neo-esencialismo de los paradigmas del pluriverso, del giro decolonial e de los settler colonial studies en los estudios latino-americanos. Conferência realizada no Panel de Académicos Distinguidos "Perspectivas Sobre Raza y Etnicidad en América Latina". V ERIP, Morélia, México, 2017.

RESENDE, Maria Leonia Chaves de. Gentios brasílicos: índios coloniais em Minas Gerais setecentista. 2003. 388 f. Tese (Doutorado em História) - Universidade Estadual de Campinas (UNICAMP), Campinas, SP, 2003.

RESÉNDEZ, Andrés. The other slavery: the uncovered story of Indian enslavement in America. Boston : Houghton Mifflin Harcourt, 2016.

RESTALL, Matthew (Org.). Beyond black and red: african-native relations in Colonial Latin America. Albuquerque: University of New Mexico Press, 2005.

RIBEIRO, Áureo Eduardo. Estradas da vida: terra e trabalho nas fronteiras agrícolas do Jequitinhonha e Mucuri, Minas Gerais. Belo Horizonte: Ed. UFMG, 2013.

SAINT-HILAIRE, Auguste. Viagem ao Espírito Santo e Rio Doce. São Paulo: Ed. USP, 1958.

SAMPAIO, Patrícia M. Política indigenista no Brasil Imperial. In: GRINBERG, Keila; SALLES, Ricardo (Org.). O Brasil Imperial (1808-1889). Rio de Janeiro: Civilização Brasileira, 2009. v. 1, p. $175-206$.

SASSOFERRATO, Frei Ângelo de. Synopse da Missão cathechética dos selvicolas do Mucury, norte do Estado de Minas Geraes. Esta Missão foi fundada em 1873, pelos Rev.mos Capuchinhos Seraphim de Gorizia e Ângelo de Sassoferrato no centro das matas, distantes 36 kilômetros ao sul da cidade de Theophilo Ottoni (antiga Philadelphia). Arquivo dos Capuchinhos do Rio de Janeiro, Gav. C, Pasta IV, 1915. 69 fls. 
SCHWARTZ, Stuart. Indian labor and new world plantations: european demands and indian responses in northeastern Brazil. The American Historical Review, [S.I.], v. 83, n. 1, p. 43-79, fev. 1978.

SENNA, Nelson de. Discurso pronunciado como orador official, na sessão inaugural, da Academia Mineira de Letras, no Theatro de Juiz de Fora, a 13 de maio de 1910. Belo Horizonte, 1910.

SPOSITO, Fernanda. As guerras justas na crise do antigo regime português: análise da política indigenista de D. João VI. Revista de História, São Paulo, n. 161, p. 85-112, 2o semestre 2009.

WEINSTEIN, Barbara. Erecting and erasing boundaries: can we combine the "Indo" and the "Afro" in Latin American studies? EIAL: Estudios Interdisciplinarios de America Latina y el Caribe, [S.I.], v. 19, n. 1, p. 129-144, 2008,

WEYRAUCH, Cléia. Pioneiros alemães de Nova Filadélfia: relato de mulheres. Caxias do Sul, RS: Educs, 1997.

WHITE, Richard. The middle ground: indians, empires, and republics in the Great Lakes region, 1650-1815. 6. ed. Cambridge, Reino Unido: Cambridge University Press, 1996.

\section{Sobre a autora:}

Izabel Missagia de Mattos: professora associada de Antropologia na Universidade Federal Rural do Rio de Janeiro, em cursos de graduação e pós-graduação nas áreas de História e Ciências Sociais. É autora de diversos artigos científicos e do livro Civilização e Revolta: os Botocudos e a catequese na Província de Minas (2004) - trabalho premiado pela Associação Nacional de Pós-Graduação e Pesquisa em Ciências Sociais (ANPOCS, 2003), fruto de pesquisa de doutorado realizada na Universidade Estadual de Campinas, sob orientação do professor John Monteiro (1956-2013). Atualmente vem investigando, com o auxílio da Fundação de Apoio à Pesquisa do Rio de Janeiro, processos referentes à memória social, paisagem e patrimônio cultural de povos indígenas em Minas Gerais. E-mail: belmissagia@gmail.com

Recebido em 29 de abril de 2018

Aprovado para publicação em 14 de junho de 2017 
